\title{
Catechol Estrogen 4-Hydroxyestradiol is an Ultimate Carcinogen in Breast Cancer
}

\author{
Sin-Aye $\operatorname{Park}^{\dagger, *}$ \\ Department of Biomedical Laboratory Science, College of Medical Sciences, \\ Soonchunhyang University, Asan 31538, Korea
}

\begin{abstract}
Excessive exposure to estrogens is the most important risk factor for the development of hormone-sensitive cancers, especially breast cancer. Estrogen stimulates the expression of genes and proteins involved in cell proliferation by binding to estrogen receptor (ER). Another possible mechanism of ER-independent carcinogenicity of estrogens is based on the hydroxylation of estradiol resulting in the formation of catechol estrogens. Catechol estrogen 4-hydroxyestradiol (4-OHE 2$)$ is further oxidized to catechol estrogen-3,4-quinones, the major carcinogenic metabolites of estrogens. Evidence increasingly supports the critical role of $4-\mathrm{OHE}_{2}$ in hormonal carcinogenesis via DNA adduct formation or production of reactive oxygen species, which finally contribute to the transformation of normal mammary epithelial cells and the enhanced growth of breast cancer cells. It is also reported that the level of 4-OHE 2 or its quinones is highly up-regulated in urine or tissues of breast cancer patients. Thus, we highlight the oncogenic roles of $4-\mathrm{OHE}_{2}$ in catechol estrogen-induced breast carcinogenesis.
\end{abstract}

Key Words: Breast cancer, Catechol estrogen-3,4-quinones, DNA adducts, 4-Hydroxyestradiol, Reactive oxygen species

\section{INTRODUCTION}

Breast cancer is one of the most frequent disorders among women worldwide. In recent years, early detection has increased the survival rate of patients. However, breast cancer remains one of the most malignant cancers with increased risk of relapse and metastasis. In particular, patients lacking estrogen receptor (ER), progesterone receptors, and hormone epidermal growth factor receptor 2, have limited treatment options (Wahba and El-Hadaad, 2015; Lukong, 2017). Therefore, it is necessary to investigate not only the mechanism of estrogen/ER-induced breast cancer but also other mech- anisms. It has been proposed that genotoxicity induced by estrogen metabolites, including 2-hydroxyestradiol $\left(2-\mathrm{OHE}_{2}\right)$ and 4-hydroxyestradiol (4- $\left.\mathrm{OHE}_{2}\right)$, may contribute to breast carcinogenesis (Cavalieri et al., 2006; Fernandez et al., 2006). Interestingly, these metabolites are involved in breast carcinogenesis mainly via DNA adducts or reactive oxygen species (ROS) formation, without essentially binding to ER (Chang, 2011; Wen et al., 2017).

Estradiol $\left(\mathrm{E}_{2}\right)$ is biosynthesized by both aromatase and $17 \beta$-estradiol dehydrogenase from androstenedione via testosterone or estrone (Zhu and Conney, 1998). This $\mathrm{E}_{2}$ is metabolized via two major pathways: formation of catechol estrogens and, to a lesser extent, 16 $\alpha$-hydroxylation (Zhu and

Received: June 7, 2018 / Revised: September 1, 2018 / Accepted: September 4, 2018

* Professor.

${ }^{\dagger}$ Corresponding author: Sin-Aye Park. Department of Biomedical Laboratory Science, College of Medical Sciences, Soonchunhyang University, Asan 31538 , Korea.

Tel: +82-41-530-4990, Fax:+82-41-530-3085, e-mail: sappark@sch.ac.kr

(C) The Korean Society for Biomedical Laboratory Sciences. All rights reserved.

(c) This is an Open Access article distributed under the terms of the Creative Commons Attribution Non-Commercial License (http://creativecommons.org/licenses/by-nc/3.0/) which 
Conney, 1998; Cavalieri et al., 2006). The catechol estrogens including 2- $\mathrm{OHE}_{2}$ and $4-\mathrm{OHE}_{2}$, are further oxidized initially to their semiquinone intermediates and then to quinone metabolites by peroxidases or cytochrome P450 (CYP)s (Zhang et al., 2007). Redox cycling via reduction of quinones to semiquinones, catalyzed by CYP reductase, and subsequent oxidation back to catechol estrogen-3,4-quinones (CE-3,4-Q) by oxygen yields super-anion radicals and hydrogen peroxide $\left(\mathrm{H}_{2} \mathrm{O}_{2}\right)$. Because quinones and semiquinones are capable of redox cycling as long as molecular oxygen is available, a minor amount of estradiol may trigger substantial cellular damage (Cavalieri et al., 2000).

Interestingly, numerous studies suggested that $4-\mathrm{OHE}_{2}$ is a more potent carcinogen than $2-\mathrm{OHE}_{2}$. The $2-\mathrm{OHE}_{2}$ has little or no carcinogenic activity compared with $4-\mathrm{OHE}_{2}$ (Liehr et al., 1986; Zhu and Conney, 1998; Newbold and Liehr, 2000). Treatment of MCF-10F cells with $E_{2}$ or 4$\mathrm{OHE}_{2}$ was mutagenic even at the lowest dose used $(0.007$ and $70 \mathrm{nM}$ ), whereas 2-OHE - -transformed cells manifested these mutations only at the highest dose $(3.6 \mu \mathrm{M})$ (Fernandez et al., 2006). The extremely weak carcinogen $2-\mathrm{OHE}_{2}$ also forms depurinating adducts, but to a much lesser extent (Zahid et al., 2006). Notably, an elevated ratio of $4-\mathrm{OHE}_{2} /$ $2-\mathrm{OHE}_{2}$ formation was detected in microsomes prepared from human mammary adenocarcinoma and fibroadenoma (Liehr and Ricci, 1996). 4-OHE 2 or its quinone conjugates were detected in human breast tumor biopsies at significantly higher levels compared with the levels in the normal breast tissues (Rogan et al., 2003). $O$-methylation of $2-\mathrm{OHE}_{2}$ is faster than that of $4-\mathrm{OHE}_{2}$ and leads to a more rapid clearance, and therefore, lacks carcinogenicity (Zhu and Conney, 1998). Here, this review summarizes the carcinogenic role of $4-\mathrm{OHE}_{2}$ through various aspects, especially in human mammary carcinogenesis (Fig. 1). Finally, this review strongly support the hypothesis that $4-\mathrm{OHE}_{2}$ is not only a tumor initiator but also an ultimate carcinogen.

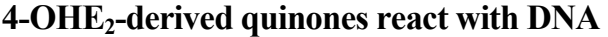

The reactive quinones derived from $4-\mathrm{OHE}_{2}$ generated depurinating DNA adducts such as $4-\mathrm{OHE}_{2}-\mathrm{N} 7$-guanine (4-OHE $-\mathrm{N} 7-\mathrm{G})$ and 4-OHE $-\mathrm{N} 3$-adenine (4-OHE 2 -N3-A) (Belous et al., 2007). The mutagenic effects of $4-\mathrm{OHE}_{2}$ were reported in $\mathrm{BB}$ rat 2 embryonic cells exposed to multiple low doses (50 200 nM) (Zhao et al., 2006). In addition, media from 4-OHE 2 -treated MCF-10F cells, which are ER-negative immortalized human breast epithelial cells, contained depurinating N7-G and N3-A adducts (Saeed et al., 2007). Mutagenic activity of 4-OHE 2 and $\mathrm{CE}-3,4-\mathrm{Q}$ have also been reported in the mammary gland of BB rats and ACI rats, respectively (Mailander et al., 2006; Zhao et al., 2006). Intramammary injection of $4-\mathrm{OHE}_{2}$ or CE-3,4-Q into female rats, followed by excision of mammary tissue $1 \mathrm{~h}$ later, revealed the presence of depurinating adducts $4-\mathrm{OHE}_{2}-\mathrm{N} 7-\mathrm{G}$ and 4-OHE $2-\mathrm{N} 3-\mathrm{A}$ (Cavalieri et al., 1997; Li et al., 2004). The intraperitoneal injection of $4-\mathrm{OHE}_{2}$ into male Syrian golden hamsters increased the formation of glutathione (GSH) and Cys conjugates of $4-\mathrm{OHE}_{2}$ and $4-\mathrm{OHE}_{2}-\mathrm{N} 7-\mathrm{G}$ adducts (Devanesan et al., 2001; Todorovic et al., 2001). Moreover, the urinary level of 4-OHE 2 -derived depurinating DNA adducts was substantially elevated in high-risk women and women diagnosed with breast cancer compared with those of the control subjects (Gaikwad et al., 2008). These adducts generate apurinic sites that may lead to cancer-initiating mutations (Chakravarti et al., 2001). It is also reported that catechol estrogens induce oxidative DNA damage (Hiraku et al., 2001). The interaction of $4-\mathrm{OHE}_{2}$ and copper induced DNA modification and damage involving single/double strand breaks, base modification and so on (Khan et al., 2007).

\section{Imbalance of estrogen metabolizing enzymes is involved in $4-\mathrm{OHE}_{2}$-induced genotoxicity}

Imbalance in estrogen homeostasis leads to substantial formation of $4-\mathrm{OHE}_{2}$ or $4-\mathrm{OHE}_{2}$-derived DNA adducts (Cavalieri and Rogan, 2006; Cavalieri and Rogan, 2016). CYP1B1, which is abundantly expressed in extrahepatic tissues such as mammary glands, ovary, and uterus, specifically catalyzes the 4-hydroxylation of $E_{2}$ and further oxidizes $4-\mathrm{OHE}_{2}$ to its semiquinone and quinone conjugates (Zhang et al., 2007). The estrogen 4-hydroxylase, CYP1B1, is also overexpressed in tumors of the breast (Murray et al., 1997; Singh et al., 2005) and promotes breast cancer cell survival (Kwon et al., 2016). In addition, CYP1B1 is genetically polymorphic, and variations in the $C Y P 1 B 1$ gene are correlated with the risk of breast cancer (Zheng et al., 2000). 


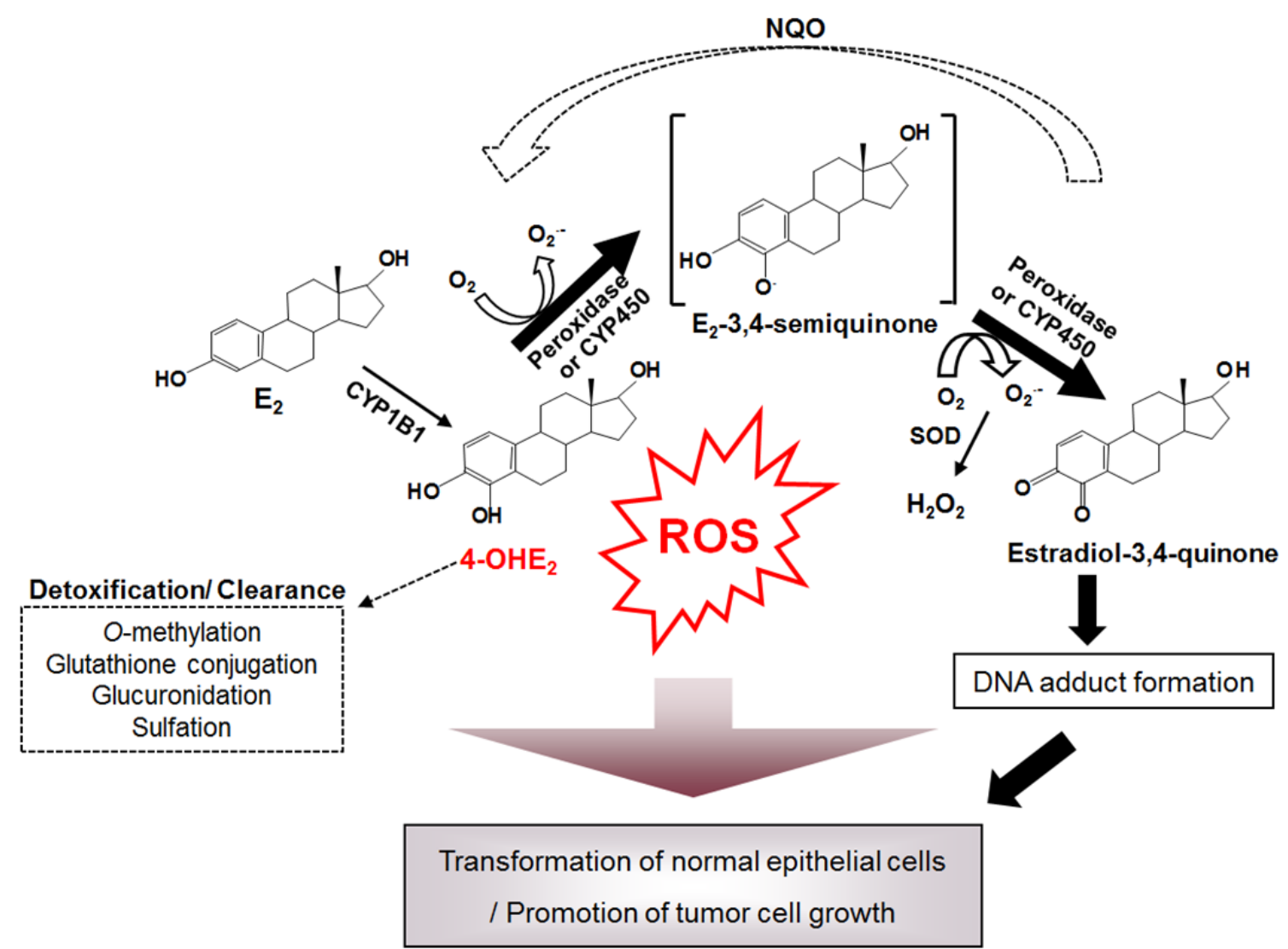

Fig. 1. Role of 4- $\mathrm{OHE}_{2}$ in hormonal carcinogenesis. $\mathrm{E}_{2}$ is catalyzed by $\mathrm{CYP} 1 \mathrm{~B} 1$ to form $4-\mathrm{OHE}_{2}$, which is further oxidized to the genotoxic estradiol-3,4-quinone. During redox cycling of 4-OHE 2 and its metabolites, $\mathrm{ROS}$ is overproduced. The reactive quinone and ROS contribute to induce the transforamtion of normal epithelial cells and promote the growth of tumor cells. Unbalanced control of estrogen-metabolizing enzymes also trigger to produce 4- $\mathrm{OHE}_{2}$-derived quinones, which can act as an ultimate carcinogen. $\mathrm{E}_{2}$ : estradiol, 4-OHE 2 : 4-hydroxyestradiol, ROS: reactive oxygen species, NQO: NAD(P)H:quinone oxidoreductase, CYP450: cytochrome P450.

In contrast, the reactivity of catechol estrogen-derived quinones can be prevented via conjugation with GSH. Further, quinone metabolites are reduced to their original catechol estrogen by $\mathrm{NAD}(\mathrm{P}) \mathrm{H}: q u i n o n e ~ o x i d o r e d u c t a s e ~(\mathrm{NQO})$ and/or CYP reductase (Roy and Liehr, 1988). If these inactivating processes are insufficient and/or ineffective or the level of CYP450s, especially CYP1B1, is abnormally high, catechol estrogen-derived quinones metabolites may react with DNA to form predominantly depurinating adducts. Additionally, the oxidation of $4-\mathrm{OHE}_{2}$ by peroxidase or CYPs contributes to ROS overproduction in human mammary epithelial MCF-10A cells. Similary, dicoumarol, the inhibitor of NQO activity, enhanced 4- $\mathrm{OHE}_{2}$-induced ROS production under similar conditions (Park et al., 2009).
Additionally, the catechol estrogens are excreted in the urine and/or feces by metabolic conversion to hormonally inactive or less active metabolites. The conjugative metabolism includes glucuronidation, sulfonation, and $O$-methylation. It has been well documented that the metabolic conjugation of estrogens by conjugating enzymes decreases their hormonal activity and facilitates their excretion (Zhu and Conney, 1998). Especially, the $O$-methylation of catechol estrogens is catalyzed by catechol-O-methyltransferase that blocks the further metabolism of catechol estrogen (Yager, 2012). This event has been reported as a critical detoxification pathway for the catechol intermediates (Zhu and Conney, 1998; Raftogianis et al., 2000). Altogether, the unbalanced regulation of estrogen metabolizing enzymes finally results in the formation 
of catechol estrogen-derived quinones resulting in carcinogenesis.

\section{4-OHE 2 produces ROS}

The catechol estrogen 4- $\mathrm{OHE}_{2}$ and its semiquinones/ quinones also undergo redox cycling, which results in the production of ROS. Excessive ROS induce oxidative DNA damage (Liehr and Roy, 1990; Nutter et al., 1994). Human breast epithelial MCF-10A cells treated with $4-\mathrm{OHE}_{2}$ increased intracellular ROS accumulation and 8-oxo-7,8dihydroxy-2'-deoxyguanosine (8-oxo-dG) formation. Further, extracellular signal-regulated protein kinases and nuclear factor- $\kappa \mathrm{B}(\mathrm{NF}-\kappa \mathrm{B})$, which are redox-sensitive molecules, were transiently activated by $4-\mathrm{OHE}_{2}$ treatment (Chen et al., 2005). It was reported that catechol metabolites of endogenous estrogens generated $\mathrm{H}_{2} \mathrm{O}_{2}$ and hydroxyl radicals in breast epithelial cells (Fussell et al., 2011). The concomitant synthesis of ROS, overproduced during redox cycling of 4- $\mathrm{OHE}_{2}$, further activated $\mathrm{I} \kappa \mathrm{B}$ kinase (IKK)-NF- $\mathrm{BB}$ signaling (Park et al., 2009) or phosphoinositide 3-kinase-Akt pathway (Okoh et al., 2013) which may result in neoplastic transformation of human mammary epithelial cells.

\section{4-OHE 2 induces neoplastic transformation of normal epithelial cells}

Transformation of normal cells into neoplastic cells results from a series of genetic and epigenetic alterations and is a critical event in induction of carcinogenesis. Multiple lines of evidence suggest that $4-\mathrm{OHE}_{2}$ contributes to neoplastic transformation of normal epithelial cells. Treatment of human breast epithelial MCF-10F cells with $\mathrm{E}_{2}$ or $4-\mathrm{OHE}_{2}$ induced neoplastic transformation, even in the presence of antiestrogen ICI-182,780 (Lareef et al., 2005). The failure of anti-estrogen to abrogate the transformation phenotypes suggests that $4-\mathrm{OHE}_{2}$-induced cell transformation is independent of ER binding. When MCF-10F cells were treated with benz(a)pyrene, $\mathrm{E}_{2}, 2-\mathrm{OHE}_{2}, 4-\mathrm{OHE}_{2}$, or $16 \alpha-\mathrm{OHE}_{2}, 4-\mathrm{OHE}_{2}$ effectively induced larger colonies and numbers at doses of $0.007 \mathrm{nM}$ (Russo et al., 2003). The effect of $4-\mathrm{OHE}_{2}$ on neoplastic transformation of human mammary epithelial cells was repeatedly observed. $4-\mathrm{OHE}_{2}$ markedly induced anchorage-independent colony formation in MCF-10A cells via activation of IKK-NF- $\kappa$ B signaling pathway (Park et al., 2009).

\section{4-OHE 2 promotes the growth of cancer cells}

$4-\mathrm{OHE}_{2}$ not only induces cell transformation in normal cells but also promotes the growth of cancer cells. Treatment with $4-\mathrm{OHE}_{2}$, but not $2-\mathrm{OHE}_{2}$, induced renal cancer in Syrian hamster (Liehr et al., 1986). The administration of $\mathrm{E}_{2}, 2-\mathrm{OHE}_{2}$, and $4-\mathrm{OHE}_{2}$ induced endometrial carcinomas in $7 \%, 12 \%$, and $66 \%$, respectively, of treated CD-1 mice (Newbold and Liehr, 2000). Interestingly, when female ACI rats were treated with $\mathrm{E}_{2}$, co-treatment with $\mathrm{E}_{2}$ plus vitamin $\mathrm{C}$ or $\mathrm{E}_{2}$ plus estrogen metabolic inhibitor $\alpha$-naphthoflavone (ANF), breast tumor incidence was $82 \%, 29 \%$ and $0 \%$, respectively. Since ANF inhibits 4-hydroxylation of $\mathrm{E}_{2}$ and decreases formation of the highly carcinogenic $4-\mathrm{OHE}_{2}$, these results suggest that $\mathrm{E}_{2}$ metabolism toward $4-\mathrm{OHE}_{2}$ pathway is critically involved in estrogen-induced breast carcinogenesis (Mense et al., 2009).

In addition, numerous studies demonstrated that $4-\mathrm{OHE}_{2}$ stimulated specific intracellular signaling molecules, which support the oncogenic role of 4-OHE 2 . Especially, the effects of estradiol metabolites on cell cycle has been well studied (Lottering et al., 1992; Lewis et al., 2001; Chang, 2011). Among those metabolites, the estrogens $\mathrm{E}_{2}, 4-\mathrm{OHE}_{2}$ and $16-\mathrm{OHE}_{1}$ showed a proliferative effect on MCF-7 human breast cancer cells which was accompanied by a downregulation of apoptosis (Seeger et al., 2006). Also, the expression of cell cycle-related genes such as cdc2, protein regulator of cytokinesis 1 , and proliferating cell nuclear antigen was up-regulated by 4-OHE 2 treatment (Okoh et al., 2013).

Generally, invasion and metastases follow the degradation of extracellular matrix (ECM), which acts as a barrier to cancer cell movement. ECM proteins are degraded by proteases, mainly the matrix metalloproteinases (MMPs) and increase the risk of invasive and metastatic processes. Enzymatic assay and gel zymography demonstrated that $4-\mathrm{OHE}_{2}$ led to the conversion of pro MMP-2 and -9 to active MMP2 and -9 , which resulted in dissemination of cancer cells (Paquette et al., 2003; Paquette et al., 2005). Further, 4-OHE 2 and not $2-\mathrm{OHE}_{2}$, induced the expression of hypoxia-inducible factor 1 and vascular endothelial growth factor A, which are 
critical molecules in angiogenesis or invasion of cancer cells (Gao et al., 2004).

\section{CONCLUSION}

Although ER-mediated hormonal carcinogenesis has been largely understood, results from cell/animal/human-based studies suggested that catechol estrogen, especially $4-\mathrm{OHE}_{2}$ acts as an ultimate carcinogen independent of ER. The catechol estrogen is further metabolized by CYP-mediated oxidation, $O$-methylation, reaction with glutathione, glucuronidation, and sulfation. Apparently, a specific equilibrium exists in the metabolic pathways of catechol estrogen to maintain hormonal homeostasis. Disturbed equilibrium may trigger carcinogenesis by increasing the levels of catechol estrogen-derived quinones. Further, semiquinones/quinones and hydroxyl radicals generated during the oxidative estrogen metabolism induce either oxidative DNA damage such as formation of 8-oxo-dG or apurinic DNA adducts (Chen et al., 2005; Fussell et al., 2011).

Previously, 4-OHE 2 treatment produced tumors in kidney of Syrian hamsters (Liehr et al., 1986) and uterine of CD-1 mice (Newbold and Liehr, 2000) rather than in mammary gland. In addition, 4-OHE 2 exposure was not sufficient to produce mammary tumors in female ACI rats (Turan et al., 2004). Since 4-OHE 2 is more water soluble and unstable than $\mathrm{E}_{2}$, Turan and his colleagues suggested that it may be critical for $4-\mathrm{OHE}_{2}$ formation in or near mammary tissues to effectively initiate carcinogenesis (Turan et al., 2004). Importantly, the level of $4-\mathrm{OHE}_{2}$ is correlated with the pathogenesis of breast cancer. Studies of breast tissue from women with and without breast cancer provide evidence to support the impact of unbalanced estrogen homeostasis on cancer (Castagnetta et al., 2002; Singh et al., 2005). The accumulation of $4-\mathrm{OHE}_{2}$ is also correlated with the invasiveness of breast cancer cells (Paquette et al., 2003; Paquette et al., 2005).

$4-\mathrm{OHE}_{2}$ acts as a tumor initiator when its quinone metabolites react with DNA and also acts as a tumor promoter through ROS overproduction. Additional induction of a number of cellular signaling pathways leads to neoplastic epithelial transformation, cell proliferation, or tumor promotion. Therefore, catechol estrogen $4-\mathrm{OHE}_{2}$ or its quinoid meta- bolites may serve as a biomarker for breast cancer and methods that facilitate the detection of these metabolites more easily and accurately are needed.

\section{ACKNOWLEDGMENTS}

This work was supported by the Soonchunhyang University Research Fund (No. 20180405).

\section{CONFLICT OF INTEREST}

The authors have no conflict of interest regarding the publication of this article.

\section{REFERENCES}

Belous AR, Hachey DL, Dawling S, Roodi N, Parl FF. Cytochrome p450 1b1-mediated estrogen metabolism results in estrogen-deoxyribonucleoside adduct formation. Cancer Res. 2007. 67: 812-817.

Castagnetta LA, Granata OM, Traina A, Ravazzolo B, Amoroso M, Miele M, Bellavia V, Agostara B, Carruba G. Tissue content of hydroxyestrogens in relation to survival of breast cancer patients. Clin Cancer Res. 2002. 8: 3146-3155.

Cavalieri E, Chakravarti D, Guttenplan J, Hart E, Ingle J, Jankowiak R, Muti P, Rogan E, Russo J, Santen R, Sutter T. Catechol estrogen quinones as initiators of breast and other human cancers: Implications for biomarkers of susceptibility and cancer prevention. Biochim Biophys Acta. 2006. 1766: 63-78.

Cavalieri E, Frenkel K, Liehr JG, Rogan E, Roy D. Estrogens as endogenous genotoxic agents--DNA adducts and mutations. J Natl Cancer Inst Monogr. 2000. 75-93.

Cavalieri E, Rogan E. Catechol quinones of estrogens in the initiation of breast, prostate, and other human cancers: Keynote lecture. Ann N Y Acad Sci. 2006. 1089: 286-301.

Cavalieri EL, Rogan EG. Depurinating estrogen-DNA adducts, generators of cancer initiation: Their minimization leads to cancer prevention. Clin Transl Med. 2016. 5: 12.

Cavalieri EL, Stack DE, Devanesan PD, Todorovic R, Dwivedy I, Higginbotham S, Johansson SL, Patil KD, Gross ML, Gooden JK, Ramanathan R, Cerny RL, Rogan EG. Molecular origin of cancer: Catechol estrogen-3,4-quinones as endogenous tumor initiators. Proc Natl Acad Sci U S A. 1997. 94: 10937 -10942 .

Chakravarti D, Mailander PC, Li KM, Higginbotham S, Zhang HL, Gross ML, Meza JL, Cavalieri EL, Rogan EG. Evidence 
that a burst of DNA depurination in sencar mouse skin induces error-prone repair and forms mutations in the h-ras gene. Oncogene. 2001. 20: 7945-7953.

Chang M. Dual roles of estrogen metabolism in mammary carcinogenesis. BMB Rep. 2011. 44: 423-434.

Chen ZH, Na HK, Hurh YJ, Surh YJ. 4-hydroxyestradiol induces oxidative stress and apoptosis in human mammary epithelial cells: Possible protection by nf-kappab and erk/mapk. Toxicol Appl Pharmacol. 2005. 208: 46-56.

Devanesan P, Todorovic R, Zhao J, Gross ML, Rogan EG, Cavalieri EL. Catechol estrogen conjugates and DNA adducts in the kidney of male syrian golden hamsters treated with 4-hydroxyestradiol: Potential biomarkers for estrogen-initiated cancer. Carcinogenesis. 2001. 22: 489-497.

Fernandez SV, Russo IH, Russo J. Estradiol and its metabolites 4-hydroxyestradiol and 2-hydroxyestradiol induce mutations in human breast epithelial cells. Int J Cancer. 2006. 118: 1862 -1868 .

Fussell KC, Udasin RG, Smith PJ, Gallo MA, Laskin JD. Catechol metabolites of endogenous estrogens induce redox cycling and generate reactive oxygen species in breast epithelial cells. Carcinogenesis. 2011. 32: 1285-1293.

Gaikwad NW, Yang L, Muti P, Meza JL, Pruthi S, Ingle JN, Rogan EG, Cavalieri EL. The molecular etiology of breast cancer: Evidence from biomarkers of risk. Int J Cancer. 2008. 122: 1949-1957.

Gao N, Nester RA, Sarkar MA. 4-hydroxy estradiol but not 2hydroxy estradiol induces expression of hypoxia-inducible factor 1alpha and vascular endothelial growth factor a through phosphatidylinositol 3-kinase/akt/frap pathway in ovcar-3 and a2780-cp70 human ovarian carcinoma cells. Toxicol Appl Pharmacol. 2004. 196: 124-135.

Hiraku Y, Yamashita N, Nishiguchi M, Kawanishi S. Catechol estrogens induce oxidative DNA damage and estradiol enhances cell proliferation. Int J Cancer. 2001. 92: 333-337.

Khan WA, Alam K, Moinuddin. Catechol-estrogen modified DNA: A better antigen for cancer autoantibody. Arch Biochem Biophys. 2007. 465: 293-300.

Kwon YJ, Baek HS, Ye DJ, Shin S, Kim D, Chun YJ. Cyplb1 enhances cell proliferation and metastasis through induction of emt and activation of wnt/beta-catenin signaling via sp1 upregulation. PLoS One. 2016. 11: e0151598.

Lareef MH, Garber J, Russo PA, Russo IH, Heulings R, Russo J. The estrogen antagonist ici-182-780 does not inhibit the transformation phenotypes induced by 17-beta-estradiol and 4-oh estradiol in human breast epithelial cells. Int J Oncol. 2005. 26: 423-429.

Lewis JS, Thomas TJ, Klinge CM, Gallo MA, Thomas T. Regulation of cell cycle and cyclins by 16alpha-hydroxyestrone in mcf-7 breast cancer cells. J Mol Endocrinol. 2001. 27: 293 -307 .

Li KM, Todorovic R, Devanesan P, Higginbotham S, Kofeler H, Ramanathan R, Gross ML, Rogan EG, Cavalieri EL. Metabolism and DNA binding studies of 4-hydroxyestradiol and estradiol-3,4-quinone in vitro and in female aci rat mammary gland in vivo. Carcinogenesis. 2004. 25: 289-297.

Liehr JG, Fang WF, Sirbasku DA, Ari-Ulubelen A. Carcinogenicity of catechol estrogens in syrian hamsters. J Steroid Biochem. 1986. 24: 353-356.

Liehr JG, Ricci MJ. 4-hydroxylation of estrogens as marker of human mammary tumors. Proc Natl Acad Sci U S A. 1996. 93: 3294-3296

Liehr JG, Roy D. Free radical generation by redox cycling of estrogens. Free Radic Biol Med. 1990. 8: 415-423.

Lottering ML, Haag M, Seegers JC. Effects of 17 beta-estradiol metabolites on cell cycle events in mcf-7 cells. Cancer Res. 1992. 52: 5926-5932.

Lukong KE. Understanding breast cancer - the long and winding road. BBA Clin. 2017. 7: 64-77.

Mailander PC, Meza JL, Higginbotham S, Chakravarti D. Induction of a.T to g.C mutations by erroneous repair of depurinated DNA following estrogen treatment of the mammary gland of aci rats. J Steroid Biochem Mol Biol. 2006. 101: 204-215.

Mense SM, Singh B, Remotti F, Liu X, Bhat HK. Vitamin c and alpha-naphthoflavone prevent estrogen-induced mammary tumors and decrease oxidative stress in female aci rats. Carcinogenesis. 2009. 30: 1202-1208.

Murray GI, Taylor MC, McFadyen MC, McKay JA, Greenlee WF, Burke MD, Melvin WT. Tumor-specific expression of cytochrome p450 cyp1b1. Cancer Res. 1997. 57: 3026-3031.

Newbold RR, Liehr JG. Induction of uterine adenocarcinoma in cd-1 mice by catechol estrogens. Cancer Res. 2000. 60: 235 -237 .

Nutter LM, Wu YY, Ngo EO, Sierra EE, Gutierrez PL, Abul-Hajj YJ. An o-quinone form of estrogen produces free radicals in human breast cancer cells: Correlation with DNA damage. Chem Res Toxicol. 1994. 7: 23-28.

Okoh VO, Felty Q, Parkash J, Poppiti R, Roy D. Reactive oxygen species via redox signaling to pi $3 \mathrm{k} / \mathrm{akt}$ pathway contribute to the malignant growth of 4-hydroxy estradiol-transformed mam- 
mary epithelial cells. PLoS One. 2013. 8: e54206.

Paquette B, Bisson M, Baptiste C, Therriault H, Lemay R, Cantin AM. Invasiveness of breast cancer cells mda-mb-231 through extracellular matrix is increased by the estradiol metabolite 4-hydroxyestradiol. Int J Cancer. 2005. 113: 706-711.

Paquette B, Bisson M, Therriault H, Lemay R, Pare M, Banville P, Cantin AM. Activation of matrix metalloproteinase-2 and -9 by 2- and 4-hydroxyestradiol. J Steroid Biochem Mol Biol. 2003. 87: 65-73.

Park SA, Na HK, Kim EH, Cha YN, Surh YJ. 4-hydroxyestradiol induces anchorage-independent growth of human mammary epithelial cells via activation of ikappab kinase: Potential role of reactive oxygen species. Cancer Res. 2009. 69: 2416-2424.

Raftogianis R, Creveling C, Weinshilboum R, Weisz J. Estrogen metabolism by conjugation. J Natl Cancer Inst Monogr. 2000. 113-124.

Rogan EG, Badawi AF, Devanesan PD, Meza JL, Edney JA, West WW, Higginbotham SM, Cavalieri EL. Relative imbalances in estrogen metabolism and conjugation in breast tissue of women with carcinoma: Potential biomarkers of susceptibility to cancer. Carcinogenesis. 2003. 24: 697-702.

Roy D, Liehr JG. Temporary decrease in renal quinone reductase activity induced by chronic administration of estradiol to male syrian hamsters. Increased superoxide formation by redox cycling of estrogen. J Biol Chem. 1988. 263: 3646-3651.

Russo J, Hasan Lareef M, Balogh G, Guo S, Russo IH. Estrogen and its metabolites are carcinogenic agents in human breast epithelial cells. J Steroid Biochem Mol Biol. 2003. 87: 1-25.

Saeed M, Rogan E, Fernandez SV, Sheriff F, Russo J, Cavalieri E. Formation of depurinating n3adenine and n7guanine adducts by mcf-10f cells cultured in the presence of 4-hydroxyestradiol. Int J Cancer. 2007. 120: 1821-1824.

Seeger H, Wallwiener D, Kraemer E, Mueck AO. Comparison of possible carcinogenic estradiol metabolites: Effects on proliferation, apoptosis and metastasis of human breast cancer cells. Maturitas. 2006. 54: 72-77.

Singh S, Chakravarti D, Edney JA, Hollins RR, Johnson PJ, West WW, Higginbotham SM, Cavalieri EL, Rogan EG. Relative imbalances in the expression of estrogen-metabolizing enzymes in the breast tissue of women with breast carcinoma. Oncol Rep. 2005. 14: 1091-1096.

Todorovic R, Devanesan P, Higginbotham S, Zhao J, Gross ML, Rogan EG, Cavalieri EL. Analysis of potential biomarkers of estrogen-initiated cancer in the urine of syrian golden hamsters treated with 4-hydroxyestradiol. Carcinogenesis. 2001. 22: 905 $-911$.

Turan VK, Sanchez RI, Li JJ, Li SA, Reuhl KR, Thomas PE, Conney AH, Gallo MA, Kauffman FC, Mesia-Vela S. The effects of steroidal estrogens in aci rat mammary carcinogenesis: 17beta-estradiol, 2-hydroxyestradiol, 4-hydroxyestradiol, 16alpha-hydroxyestradiol, and 4-hydroxyestrone. J Endocrinol. 2004. 183: 91-99.

Wahba HA, El-Hadaad HA. Current approaches in treatment of triple-negative breast cancer. Cancer Biol Med. 2015. 12: 106 -116 .

Wen C, Wu L, Fu L, Wang B, Zhou H. Unifying mechanism in the initiation of breast cancer by metabolism of estrogen (review). Mol Med Rep. 2017. 16: 1001-1006.

Yager JD. Catechol-o-methyltransferase: Characteristics, polymorphisms and role in breast cancer. Drug Discov Today Dis Mech. 2012. 9: e41-e46.

Zahid M, Kohli E, Saeed M, Rogan E, Cavalieri E. The greater reactivity of estradiol-3,4-quinone vs estradiol-2,3-quinone with DNA in the formation of depurinating adducts: Implications for tumor-initiating activity. Chem Res Toxicol. 2006. 19: $164-172$

Zhang Y, Gaikwad NW, Olson K, Zahid M, Cavalieri EL, Rogan EG. Cytochrome p450 isoforms catalyze formation of catechol estrogen quinones that react with DNA. Metabolism. 2007. 56: 887-894.

Zhao Z, Kosinska W, Khmelnitsky M, Cavalieri EL, Rogan EG, Chakravarti D, Sacks PG, Guttenplan JB. Mutagenic activity of 4-hydroxyestradiol, but not 2-hydroxyestradiol, in bb rat2 embryonic cells, and the mutational spectrum of 4-hydroxyestradiol. Chem Res Toxicol. 2006. 19: 475-479.

Zheng W, Xie DW, Jin F, Cheng JR, Dai Q, Wen WQ, Shu XO, Gao YT. Genetic polymorphism of cytochrome p450-1b1 and risk of breast cancer. Cancer Epidemiol Biomarkers Prev. 2000. 9: 147-150.

Zhu BT, Conney AH. Functional role of estrogen metabolism in target cells: Review and perspectives. Carcinogenesis. 1998. 19: $1-27$

https://doi.org/10.15616/BSL.2018.24.3.143

Cite this article as: Park SA. Catechol Estrogen 4Hydroxyestradiol is an Ultimate Carcinogen in Breast Cancer. Biomedical Science Letters. 2018. 24: 143-149. 